\title{
Efektivitas Aromaterapi Lavender dan Peppermint Terhadap Skala Nyeri Haid Pada Remaja Putri
}

\author{
Lia Fitrial , Anisa Febrianti ${ }^{2}$, Arifah Arifin ${ }^{3}$, Arifatul Hasanah ${ }^{4}$, Dianatul Firdausiyeh ${ }^{5}$ \\ Fakultas Ilmu Kesehatan Universitas Ibrahimy ${ }^{12345}$ \\ ${ }^{1}$ leeafitria@gmail.com
}

\begin{abstract}
Adolescent girls will experience changes in the reproductive system marked by menstruation. Menstruation experienced in adolescents is often accompanied by complaints of menstrual pain. Menstrual pain can interfere with daily activities, so it requires treatment to reduce menstrual pain. One way of handling that can be done is with aromatherapy. Lavender and peppermint aromatherapy is a treatment that uses lavender and peppermint essential oils which contain linalool and linalyl acetate which are useful for reducing menstrual pain. The purpose of this study was to determine the effectiveness of lavender aromatherapy with peppermint on the menstrual pain scale in adolescent girls. The research design used was quantitative, quasi-experimental method with a two-group pre-test and post-test design with a sample of 14 respondents, 7 respondents in the lavender aromatherapy group and 7 respondents in the peppermint aromatherapy group. The sampling technique used consecutive sampling. The instrument used is a numerical rating scale (NRS). Data were processed by Wilcoxon test and Mann Whitney test. The results of this study indicate that lavender aromatherapy and lemon aromatherapy are effective in reducing menstrual pain scale with $p$ value $0.001(p<0.05)$. Levender aromatherapy and peppermint aromatherapy were effective in reducing menstrual pain scale, but there was no significant difference in reducing pain scale in both lavender and peppermint therapy groups.
\end{abstract}

Keywords: lavender aromatherapy; peppermint aromatheraphy; menstrual pain scale; adolescent women

\begin{abstract}
ABSTRAK
Remaja putri akan mengalami perubahan pada sistem reproduksi ditandai dengan menstruasi. Menstruasi yang dialami pada remaja sering disertai dengan keluhan nyeri haid. Nyeri haid dapat mengganggu aktivitas seharihari, sehingga memerlukan penanganan untuk mengurangi nyeri haid. Salah satu cara penanganan yang dapat dilakukan yaitu dengan aromaterapi. Aromaterapi lavender dan peppermint merupakan penanganan yang menggunakan minyak essensial lavender dan peppermint yang didalamnya terdapat kandungan linalool dan linalyl asetat yang bermanfaat untuk mengurangi nyeri haid. Tujuan penelitian ini adalah untuk mengetahui efektivitas aromaterapi lavender dengan peppermint terhadap skala nyeri haid pada remaja putri. Desain penelitian yang digunakan kuantitatif, metode quasy experiment dengan rencangan two group pre-test and post-test design dengan sampel 14 responden, 7 responden kelompok aromaterapi lavender dan 7 responden kelompok aromaterapi peppermint. Teknik pengambilan sampel menggunakan consecutive sampling. Instrumen yang digunakan adalah numeric rating scale (NRS). Data diolah dengan uji Wilcoxon dan uji Mann Whitney. Hasil penelitian ini menunjukkan bahwa aromaterapi lavender dan aromaterapi lemon efektif dalam menurunkan skala nyeri haid dengan $\mathrm{p}$ value $0,001(\mathrm{p}<0,05)$. Aromaterapi levender dan aromaterapi peppermint efektif dalam menurunkan skala nyeri haid, tetapi tidak ada perbedaan yang signifikan pada penurunan skala nyeri pada kelompok terapi baik lavender maupun peppermint.
\end{abstract}

Kata Kunci: aromaterapi lavender; aromaterapi peppermint; skala nyeri haid; remaja putri 

Vol. 16 No. 3 September - Desember 2021

\section{PENDAHULUAN}

Latar Belakang

Masa remaja merupakan masa transisi yang ditandai dengan perubahan fisik, emosi dan perkembangan psikis. Masa remaja juga merupakan masa pematangan organ reproduksi dan sering disebut pubertas. Pubertas dapat ditandai dengan pertumbuhan tubuh yang cepat, perubahan fungsi genetalia, dan adanya menarche (menstruasi pertama). Proses menstruasi berlangsung secara teratur setiap bulan pada setiap wanita normal dimulai sekitar 14 hari setelah ovulasi. $^{(1)}$

Dismenore merupakan nyeri perut bagian bawah yang terjadi selama haid atau menstruasi. Rasa nyeri yang dirasakan seperti kram dan dapat menyebar ke paha atau tulang belakang bagian bawah. Dismenore diklasifikasikan menjadi primer dan sekunder. Dismenore primer yaitu nyeri pada perut bagian bawah saat haid tanpa adanya kelainan atau penyakit pada panggul. Sedangkan dismenore sekunder yaitu nyeri perut bagian bawah saat haid disertai adanya kelainan atau penyakit pada panggul seperti endometriosis, radang panggul kronis dan fibroid rahim. ${ }^{(2)}$ Prevalensi kejadian dismenore masih tinggi, angka kejadian dismenore dunia mencapai $90 \%$. Menurut data World Health Organization (WHO, 2012), kejadian 1.769.425 penduduk (90\%) Wanita yang mengalami dismenorea dengan 10 $15 \%$ mengalami tingkat berat. Diperkirakan 50\% dari semua wanita di dunia menderita dismenorea dalam siklus menstruasi. Angka kejadian dismenore di Indonesia berjumlah 107.673 orang $(64,25 \%)$, terdiri dari 59.671 orang $(54,89 \%)$ mengalami dismenore primer.

Penanganan pada remaja yang mengalami nyeri haid dapat dilakukan secara farmakologi dan non farmakologi. Penatalaksanaan secara farmakologi yaitu dengan pemberian Non Steroid Anti Inflammatory Drugs (NSAID), namun, ada efek samping yang terkait dengan penggunaan NSAID tersebut termasuk ketidaknyamanan system pencernaan, perdarahan, dan risiko system kardiovaskular secara umum. ${ }^{(3)}$ Sedangkan penatalaksanaan secara non farmakologi seperti terapi akupunktur, akupresur, yoga, meditasi, dan aromaterapi. Salah satu penatalaksanaan non farmakologi yang di lakukan pada penelitian ini untuk nyeri haid yaitu dengan menggunakan aromaterapi lavender dan peppermint. Aromaterapi merupakan minyak esensial aromatik yang diekstrak dari tumbuhan alami untuk meningkatkan kesehatan tubuh, pikiran, dan jiwa. Secara tradisional, aromaterapi telah digunakan untuk mengurangi gejala dismenore, melepaskan kram rahim, dan mengurangi rasa sakit dan kecemasan setelah melahirkan. ${ }^{(4)}$ Pada aromaterapi lavender terdapat kandungan utamanya yaitu linalyl asetat dan linalool, dimana linalyl asetat berfungsi untuk mengendorkan dan melemaskan sistem kerja saraf dan otot yang mengalami ketegangan sedangkan linalool berperan sebagai relaksasi dan sedatif sehingga dapat menurunkan nyeri haid. ${ }^{(5)}$ Pada kandungan aromaterapi peppermint oil memberikan efek positif bagi tubuh dimana peppermint oil mengandung menthol, menthone, cineol dan viltaile oil yang memberikan efek melegakan mulut serta memberikan efek nyaman, rileks serta meningkatkan kondisi gastro intestinal. ${ }^{(6)}$ Berdasarkan hasil studi pendahuluan yang dilakukan oleh peneliti dengan remaja putri usia 13 - 20 tahun di Desa Kendit melalui pengisian kuesioner didapatkan bahwa 10 (67\%) remaja mengalami nyeri haid dan 5 (33\%) remaja lainnya tidak mengalami nyeri haid. Sedangkan untuk tingkat skala nyeri haid, didapatkan 11 remaja $(73,3 \%)$ yang mengalami nyeri ringan, 3 remaja (20\%) yang mengalami nyeri sedang dan 1 remaja $(6,7 \%)$ yang mengalami nyeri berat. Pada latar belakang tersebut, maka peneliti tertarik untuk mengetahui perbedaan efektivitas aromaterapi lavender dan peppermint terhadap skala nyeri haid pada remaja putri.

\section{METODE}

Desain penelitian yang digunakan dalam penelitian ini adalah quasi eksperimental with control group design. Penelitian ini dilakukan dengan cara membagi subyek penelitian menjadi dua kelompok yaitu kelompok kontrol dan kelompok intervensi. Masing-masing kelompok dilakukan pengamatan awal (pre-test) terlebih dahulu sebelum diberikan perlakuan berupa aromaterapi lavender pada kelompok intervensi dan pada kelompok kontrol diberikan peppermint, kemudian dilakukan pengamatan akhir (post-test) setelah diberikan intervensi. Teknik pengambilan sampel dalam penelitian ini menggunakan consecutive sampling sebanyak 14 responden yang memenuhi kriteria inklusi dan eksklusi. Kriteria inklusi dari penelitian ini adalah remaja usia $13-20$ tahun, nyeri haid pada hari ke $1-7$, bersedia menjadi responden. Sedangkan kriteria eksklusi penelitian ini adalah alergi pada lavender atau peppermint, tidak bersedia menjadi responden. Responden kelompok intervensi 
diberikan aromaterapi lavender selama 15 menit. Sedangkan pada kelompok kontrol diberikan aromaterapi peppermint selama 15 menit. Aromaterapi lavender dan aromaterapi peppermint diberikan secara inhalasi menggunakan diffuser. Dosis minyak essensial lavender dan peppermint yang digunakan sebanyak 3 tetes dalam 5cc air. Posisi responden tidur terlentang dan pintu ruangan dan jendela ditutup, dan diffuser diletakkan $60 \mathrm{~cm}$ di atas kepala responden. Setelah selesai pemberian aromaterapi selama 15 menit, peneliti mengukur skala nyeri responden setelah diberikan aromaterapi lavender dan aromaterapi peppermint. Intervensi kedua kelompok hanya dilakukan pada satu kali pertemuan, dan mencatat hasil pengukuran dalam lembar observasi. Hasil penelitian ini didapatkan terjadi penurunan skala nyeri pada semua responden. Analisis univariat dilakukan untuk melihat distribusi dan frekuensi usia pada kelompok lavender dan peppermint. Analisis bivariat dilakukan untuk menguji interaksi antar dua variabel dengan menggunakan uji Wilcoxon dan Mann Whitney. Instrumen yang digunakan dalam penelitian ini adalah NRS atau skala penilaian numerik untuk mengukur nyeri yang dialami oleh responden. Subyek penelitian ini berjumlah 14 responden, dan didapatkan kelompok terapi lavender sebanyak 7 responden, dan terapi peppermint sebanyak 7 responden.

\section{HASIL}

Tabel 1. Karakteristik responden kelompok lavender dan peppermint

\begin{tabular}{|c|c|c|c|c|}
\hline $\begin{array}{c}\text { Usia } \\
\text { (Tahun) }\end{array}$ & $\begin{array}{c}\text { Laven } \\
\text { der }\end{array}$ & $\begin{array}{c}\text { Prosen } \\
\text { tase } \\
(\%)\end{array}$ & $\begin{array}{c}\text { Pepper } \\
\text { mint }\end{array}$ & $\begin{array}{c}\text { Prosen } \\
\text { tase (\%) }\end{array}$ \\
\hline $13-15$ & 6 & 86 & 6 & 86 \\
\hline $16-20$ & 1 & 14 & 1 & 14 \\
\hline Jumlah & 7 & 100 & 7 & 100 \\
\hline
\end{tabular}

Berdasarkan tabel 1 menunjukkan bahwa sebagian besar karakteristik usia responden pada rentang $13-15$ tahun.

Tabel 2. Gambaran Skala Nyeri Sebelum Intervensi

\begin{tabular}{|l|l|c|}
\hline \multicolumn{1}{|c|}{ Kelompok } & \multicolumn{1}{|c|}{ Skala Nyeri } & n (\%) \\
\hline Lavender & Tidak Nyeri (0) & 0 \\
\hline & Ringan $(1-3)$ & $1(14 \%)$ \\
\hline & Sedang $(4-6)$ & $3(43 \%)$ \\
\hline & $\begin{array}{l}\text { Berat terkontrol } \\
(7-9)\end{array}$ & $3(43 \%)$ \\
\hline \multicolumn{2}{|c|}{ Jumlah } & $7(100 \%)$ \\
\hline Peppermint & Tidak Nyeri (0) & 0 \\
\hline
\end{tabular}

\begin{tabular}{|l|l|c|}
\hline & Ringan $(1-3)$ & $2(28,5 \%)$ \\
\hline & Sedang (4-6) & $2(28,5 \%)$ \\
\hline & $\begin{array}{l}\text { Berat terkontrol } \\
(7-9)\end{array}$ & $3(43 \%)$ \\
\hline \multicolumn{2}{|c|}{ Jumlah } & $7(100 \%)$ \\
\hline
\end{tabular}

Berdasarkan tabel 5.2 menunjukkan bahwa gambaran skala nyeri responden sebelum diberi aromaterapi lavender sebagian besar pada skala nyeri sedang (skala 4 -6) dan berat (skala 7 -9) sebanyak $43 \%$, sedangkan pada aromaterapi peppermint, skala nyeri responden sebelum diberikan aromaterapi sebagian besar pada skala nyeri berat (skala 7 -9) sebanyak $43 \%$.

Tabel 3. Gambaran Skala Nyeri Setelah Intervensi

\begin{tabular}{|l|l|c|}
\hline Kelompok & \multicolumn{1}{|c|}{ Skala Nyeri } & n (\%) \\
\hline Lavender & Tidak Nyeri (0) & $2(28,5 \%)$ \\
\hline & Ringan (1-3) & $3(43 \%)$ \\
\hline & Sedang (4-6) & $2(28,5 \%)$ \\
\hline & $\begin{array}{l}\text { Berat terkontrol (7 } \\
-9)\end{array}$ & 0 \\
\hline \multicolumn{2}{|c|}{ Jumlah } & $7(100 \%)$ \\
\hline Peppermint & Tidak Nyeri (0) & $1(14 \%)$ \\
\hline & Ringan (1-3) & $3(43 \%)$ \\
\hline & Sedang (4-6) & $3(43 \%)$ \\
\hline & $\begin{array}{l}\text { Berat terkontrol (7 } \\
-9)\end{array}$ & 0 \\
\hline \multicolumn{2}{|c|}{ Jumlah } & $7(100 \%)$ \\
\hline
\end{tabular}

Berdasarkan tabel 3 menunjukkan gambaran skala nyeri responden setelah diberikan aromaterapi lavender Sebagian besar pada skala nyeri ringan $(1-3)$ sebanyak $43 \%$, sedangkan pada aromaterapi peppermint mayoritas pada skala Ringan ( $1-3)$ dan Sedang $(4-6)$ sebanyak $43 \%$.

Tabel 4. Perbedaan Skala Nyeri Sebelum dan Sesudah diberikan Aromaterapi

\begin{tabular}{|l|l|l|l|l|c|}
\hline \multicolumn{2}{|c|}{ Kelompok } & n & Median & Mean \pm SD & $p$ \\
\hline \multirow{2}{*}{$\begin{array}{l}\text { Laven } \\
\text { der }\end{array}$} & Pre & 7 & $6(5-8)$ & $5,86 \pm 1,95$ & \\
\cline { 2 - 5 } & Post & 7 & $3(1-4)$ & $2,29 \pm 1,98$ & \\
\hline $\begin{array}{l}\text { Pepper } \\
\text { mint }\end{array}$ & Pre & 7 & $6(5-8)$ & $5,86 \pm 2,34$ & 0,001 \\
\cline { 2 - 5 } & Post & 7 & $3(1-4)$ & $2,57 \pm 1,90$ & \\
\hline
\end{tabular}

Perbedaan skala nyeri antara sebelum dan sesudah diberikan aromaterapi lavender dan peppermint dapat diketahui melalui uji Wilcoxon. Hasil statistik uji Wilcoxon dapat dilihat pada tabel 4 dan menunjukkan nilai $\mathrm{p}<0,05$ yang artinya ada perbedaan skala nyeri yang signifikan baik sebelum maupun sesudah intervensi pada kelompok lavender $(\mathrm{p}=0,001)$, dan kelompok peppermint $(\mathrm{p}=0,001)$. 

Vol. 16 No. 3 September - Desember 2021

Tabel 5. Perbedaan Penurunan Skala Nyeri Pada Kelompok Lavender \& Peppermint

\begin{tabular}{|l|c|c|c|c|}
\hline \multicolumn{2}{|c|}{ Kelompok } & n & Mean & p \\
\hline Lavender & Pre & 7 & 5,86 & \multirow{2}{*}{0,493} \\
\hline & Post & 7 & 2,43 & \\
\hline Peppermint & Pre & 7 & 5,86 & \multirow{2}{*}{0,493} \\
\hline & Post & 7 & 2,43 & \\
\hline
\end{tabular}

Perbedaan selisih penurunan skala nyeri pada kelompok aromaterapi lavender dan peppermint dapat diketahui melalui uji Mann-Whitney. Hasil statistik uji dapat dilihat pada tabel 5 menunjukkan bahwa secara statistik tidak ada perbedaan yang signifikan pada penurunan skala nyeri pada kelompok terapi baik lavender maupun peppermint $(\mathrm{p}>0,005)$. Hal tersebut menunjukkan bahwa Ha ditolak.

\section{PEMBAHASAN}

Responden dalam penelitian ini adalah remaja dengan keluhan nyeri haid sebelum, saat dan setelah haid dengan jumlah 14 responden. Responden dibagi menjadi 2 kelompok intervensi, yakni 7 responden dengan intervensi aromaterapi lavender, dan 7 responden dengan intervensi aromaterapi peppermint. Berdasarkan tabel 1 menunjukkan bahwa sebagian besar karakteristik usia responden pada rentang $13-15$ tahun. Responden yang mengalami menstruasi pertama kali (menarche) dalam penelitian ini Sebagian besar berusia 12 dan 13 tahun. Hal ini sesuai dengan teori yang dikemukakan oleh Sukarni dan Wahyu dimana menarche diartikan sebagai permulaan menstruasi pada seorang gadis selama masa pubertas yang biasanya muncul pada usia 11 sampai 14 tahun. Terjadinya menarche pada seseorang menunjukkan bahwa kadar estrogen dan progesteron sudah memadai untuk menginduksi perkembangan uterus.

Hasil pretest didapatkan responden yang diberikan aromaterapi lavender sebagian besar merasakan skala nyeri sedang dan skala nyeri berat sebanyak 3 responden (43\%). Sedangkan, pada aromaterapi peppermint hasil pretest didapatkan Sebagian besar merasakan skala nyeri berat sebanyak 3 responden (43\%). Dari hasil pretest yang dilakukan peneliti didapatkan bahwa nilai rata-rata sebelum pemberian aromaterapi lavender adalah 5,86 dengan standar deviasi 1,95. Pada aromaterapi peppermint didapatkan bahwa nilai rata-rata sebelum pemberian aromaterapi lavender adalah 5,86 dengan standar deviasi 2,34. Berdasarkan hasil tersebut dapat disimpulkan bahwa sebagian besar nyeri menstruasi yang dirasakan remaja putri adalah nyeri menstruasi dengan skala nyeri sedang dan nyeri berat yang mana pada skala nyeri ini dapat mengganggu aktivitas serta mengganggu konsentrasi belajar, sehingga memerlukan istirahat dan memerlukan obat-obatan untuk menghilangkan nyeri.

Terapi dengan menggunakan Aromaterapi Lavender dan Peppermint berlangsung pada saat hari pertama responden nyeri menstruasi. Dalam melaksanakan terapi masing - masing responden diminta menghirup Aromaterapi Lavender dan Peppermint selama 15 menit. Dilakukan pengisian lembar posttest menggunakan skala nyeri NRS kepada responden untuk mengukur skala nyeri setelah diberikan Aromaterapi Lavender dan Peppermint. Hasil posttest pada kelompok pemberian aromaterapi lavender didapatkan skala nyeri menstruasi dengan responden yang merasakan skala nyeri ringan sebanyak 3 responden $(43 \%)$, nyeri ringan dan tidak nyeri sebanyak 2 responden $(28,5 \%)$. Sedangkan, hasil posttest pada kelompok peppermint didapatkan skala nyeri menstruasi dengan responden yang merasakan skala nyeri ringan dan sedang sebanyak 3 responden (43\%), dan tidak nyeri sebanyak 1 responden (14\%). Dari hasil posttest yang dilakukan peneliti didapatkan bahwa nilai rata-rata setelah pemberian aromaterapi lavender adalah 2,29 dengan standar deviasi 1,98. Pada aromaterapi peppermint didapatkan bahwa nilai rata-rata setelah pemberian aromaterapi peppermint adalah 2,57 dengan standar deviasi 1,90 .

Perbedaan skala nyeri antara sebelum dan sesudah diberikan aromaterapi lavender dan peppermint dapat diketahui melalui uji Wilcoxon. Hasil statistik uji Wilcoxon dapat dilihat pada tabel 5.4 dan menunjukkan nilai $\mathrm{p}<0,05$ yang artinya ada perbedaan skala nyeri yang signifiikan baik sebelum maupun sesudah intervensi pada kelompok lavender $(\mathrm{p}=0,001)$, dan kelompok peppermint $\quad(\mathrm{p}=0,001)$. Perbedaan selisih penurunan skala nyeri pada kelompok aromaterapi lavender dan peppermint dapat diketahui melalui uji Mann-Whitney. Hasil statistik uji dapat dilihat pada tabel 5 menunjukkan bahwa secara statistik tidak ada perbedaan yang signifikan pada penurunan skala nyeri pada kelompok terapi baik lavender maupun peppermint $(\mathrm{p}>0,005)$. Hal tersebut menunjukkan bahwa Ha ditolak.

Aromaterapi didefinisikan sebagai minyak aromatik yang diekstrak dari tumbuhan dan bunga-bungaan berupa aromaterapi yang harum 
dan menyenangkan yang dapat meningkatkan kesehatan. Aromaterapi merupakan cara efektif dan lembut untuk meningkatkan kesehatan tubuh dan untuk rileks. Aroma minyak esensial ini akan memicu terjadinya reaksi dalam indera penciuman yang kemudian mengirimkan pesanpesan tersebut kepada otak sehingga menimbulkan efek relaksasi yang positif yang dapat menurunkan nyeri. Cara kerja bahan aroma terapi adalah melalui sistem sirkulasi tubuh dan sistem penciuman, dimana bau merupakan suatu molekul yang mudah menguap apabila masuk ke rongga hidung melalui pernafasan kemudian akan diterjemahkan oleh otak sebagai proses penciuman. Melalui penghirupan sebagian molekul akan masuk ke paru, kemudian molekul aromatik akan diserap oleh lapisan mukosa pada saluran pernafasan, baik pada bronkus atau pada cabang halus (bronchiole) dan terjadi pertukaran gas didalam alveoli. Molekul tersebut akan diangkut oleh sistem sirkulasi darah didalam paru. Pernafasan yang dalam akan meningkatkan jumlah bahan aromatik yang ada ke dalam tubuh. $^{(7)}$ Aromaterapi yang digunakan dalam penelitian ini adalah aromaterapi lavender dan peppermint. Hasil penelitian menunjukkan adanya penurunan nyeri setelah diberikan aromaterapi lavender dan peppermint, yang artinya baik pada aromaterapi lavender maupun peppermint sama-sama dapat menurunkan nyeri. Hal ini disebabkan karena efek dari aromaterapi lavender maupun peppermint mampu mengurangi rasa lelah, dan membuat tubuh menjadi rileks. Aromaterapi lavender (Lavendula Augustfolia) mempunyai kandungan zat aktif berupa linalool dan linalyl yang dapat berfungsi sebagai analgetik, serta dapat meningkatkan hormon endorpin sebagai akibat rangsangan hipotalamus oleh aromaterapi lavender (Lavendula Augustfolia), dapat menghasilkan rasa tenang, rasa bahagia dan relaks, serta melemasakan otot otot yang tegang akibat rasa nyeri, sehingga rasa nyeri haid yang dialami remaja putri dapat berkurang dengan terapi inhalasi aromaterapi lavender (Lavendula Augustfolia) dan sejauh ini tidak diketahui adanya kontraindikasi serta efek samping penggunaan inhalasi aromaterapi lavender. ${ }^{(8)}$ Aromaterapi peppermint mengandung menthol yang berfungsi sebagai anestesi ringan yang bersifat sementara dan efektif sebagai salah satu mekanisme anti konvulsi dan spasmolitik secara in vitro pada otot skeletal, sehingga sesuai apabila digunakan pada keluhan nyeri pada tulang, otot halus saluran gastrointestinal dan saluran empedu. ${ }^{(9)}$ Kandungan menthol (sensasi dingin) lebih efektif bila digunakan sebagai muscle relaxant dengan cara dioles, karena menthol lebih cepat meresap melalui kulit, dan mampu mengurangi cedera pada atletik, nyeri otot, kram saat menstruasi serta berbagai masalah pencernaan termasuk kembung, mual, morning sickness, dan kram perut. Kandungan menthol pada peppermint sifatnya hanya sementara bila diberikan dengan cara inhalasi, namun lebih efektif bila digunakan untuk pijat/ dioleskan ke tubuh. ${ }^{(10)}$

\section{KESIMPULAN}

Berdasarkan hasil penelitian mengenai perbedaan rata-rata penurunan nyeri haid primer untuk pemberian aromaterapi lavender dan peppermint pada remaja putri usia 13 - 21, maka dapat disimpulkan bahwa: Karakteristik responden pada kelompok lavender dan peppermint mayoritas berusia 13 - 15 tahun, Gambaran skala nyeri sebelum intervensi pada kelompok lavender Sebagian besar pada skala 4 6 (Sedang) dan 7 - 9 (berat). Sedangkan pada kelompok peppermint, Sebagian besar pada skala 7 - 9 (berat). Gambaran skala nyeri setelah intervensi pada kelompok lavender Sebagian besar pada skala 1 - 3 (Ringan). Sedangkan pada aromaterapi peppermint Sebagian besar yaitu pada skala 1 - 3 (Ringan) dan 4 - 6 (Sedang). Terdapat perbedaan yang signifikan skala nyeri antara sebelum dan sesudah intervensi atau perlakuan pada kelompok lavender dan kelompok peppermint.

\section{DAFTAR PUSTAKA}

Savitri R, Hardyanti O. The Effectiveness of Lavender Aromatherapy in Reducing the Level of Dysmenorrhea in Adolescent Girls. J Matern Care Reprod Heal. 2019;2(3):234-9.

Yunita Arga Dini DB. Innovation in Health for Society Short Clinical Review Innovation in Management of Dysmenorrhea: A nursing approach. 2021;1(1):2020-2.

Zayeri F, Dehkordi ZR, Hosseini-Baharanchi FS. The clinical efficacy of lavender oil inhalation on intensity of menstrual pain from primary dysmenorrhea. J HerbMed Pharmacol. 2019;8(3):218-23.

Thenmozhi P, Bhuvaneshwari K. Effectiveness of Aromatherapy on Menstrual Distress among Adolescent Girls. J Complement Altern Med Res. 2020;11(2):25-32.

Nikjou R, Kazemzadeh R, Rostamnegad M, Moshfegi S, Karimollahi M, Salehi H. The 
effect of lavender aromatherapy on the pain severity of primary dysmenorrhea: A triple-blind randomized clinical trial. Ann Med Health Sci Res. 2016;6(4):211.

Balakrishnan A. Therapeutic uses of peppermint A review. J Pharm Sci Res. 2015;7(7):474-6.

Zuddin RR, Abadi H, et al. Pembuatan dan Uji Hedonik Lilin Aromaterapi Dari Minyak Daun Mint (Mentha piperita L.) dan Minyak Rosemary (Rosmarinus officinalis). Jurnal Dunia Farmasi Ind. 2019;3(2):79-90.

Malloggi E, Menicucci D, Cesari V, Frumento S, Gemignani A, Bertoli A. Lavender aromatherapy: A Systematic Review From Essential Oil Quality And Administration Methods To Cognitive Enhancing Effects. Appl Psychol Heal Well-Being. 2021;(September):1-28.

Rahayuningsih T. Efektifitas Pemberian Aromaterapi Peppermint Dengan Masalah Mual Dan Muntah Pada Ibu Hamil Trimester I Di Kelurahan Sukoharjo. Int J Med Sci [Internet]. 2020;7(2):167-76.

Meamarbashi A. Instant effects of peppermint essential oil on the physiological parameters and exercise performance. Avicenna $\mathrm{J}$ phytomedicine [Internet]. 2014;4(1):72-8. 